\title{
Global clotting assays - monitoring the effect of by-passing agents in haemophilia patients with inhibitors
}

\author{
Margit Șerban ${ }^{1, *}$, Dan Poenaru², Laura Cernat ${ }^{3}$, \\ Delia Savescu ${ }^{3}$, Jenel Pătrașcu', Wolfgang Schramm \\ Emilia Ursu ${ }^{3}$, Delia Mihailov ${ }^{4}$, Cristian Jinca ${ }^{4}$, Ioana Ioniță ${ }^{4}$, Smaranda Arghirescu ${ }^{4}$ \\ ${ }^{1}$ Department of Onco-hematology, Emergency Children Hospital “Louis Turcanu” Timișoara, Romania, \\ ${ }^{2}$ Romanian Academy of Medical Science, Timisoara University of Medicine and Pharmacy \\ "Victor Babes", Timișoara, Romania, \\ ${ }^{3}$ Emergency Children Hospital "Louis Turcanu” Timișoara, Romania, \\ ${ }^{4}$ University of Medicine and Pharmacy "Victor Babes", Timisoara, Romania, \\ ${ }^{5}$ Ludwig-Maximilian Universitat, München, Germany
}

\begin{abstract}
The development of FVIII/FIX inhibitor alloantibodies represents a severe complication requiring specific laboratory evaluation for establishing a life-saving therapy regimen. Our preliminary study aimed at elaborating a laboratory strategy for monitoring the effectiveness of Activated Prothrombin Complex Concentrate (APCC) and recombinant activated factor VII (rFVIII) in haemophiliacs with inhibitors, by checking the reliability and clinical value of three complementary assays: clotting-time based coagulometry, thrombelastography (TEG) and thrombin generation assay (TGA). The investigations were performed on 7 patients with severe haemophilia $A$ with high titer inhibitors treated for 12 episodes of severe bleedings, 5 of them for surgical interventions. After the administration of bypassing agents (BPAs) the clotting-time based assay brought changes only on prothrombin ( $<<0.01)$, potentially signaling a thrombotic risk, without any impact on the global hemostasis. TEG displayed prompt significant improvement only after $r F V I I a(90 \mu \mathrm{g} / \mathrm{kg})$. TGA revealed significantly improved values for peak and velocity index, time to peak and start tail after both BPAs. Despite some disparities between biological hemostatic phenotype and clinical response to therapy, we concluded that TEG and TGA are the only current exploratory assays, expressing the quality of haemostatic control, representing a real support for a personalized, adapted therapy in hemophilia with inhibitors.
\end{abstract}

Keywords: haemophilia, inhibitors, TGA, TEG.

Received: $7^{\text {th }}$ September 2016; Accepted: 27 $7^{\text {th }}$ February 2017; Published: $31^{\text {th }}$ March 2017

* Corresponding author: Margit Șerban, Department of Onco-hematology, Emergency Children Hospital “Louis Turcanu” Timişoara, 2nd Dr. Iosif Nemoianu, Timișoara, Romania, e-mail: mserban@spitalcopiitm.ro 


\section{Introduction}

At present, haemophilia, although not curable, is a successfully treatable disease by replacement with the deficient coagulation factor. Its main therapeutically-induced complication, the occurrence of neutralizing inhibitors, is also well controlled with the use of by-passing agents (BPAs) (1-4).

Despite all successes registered in the field of haemophilia treatment, there are some limits and controversies. Inter- or even intra-individual clinical phenotypic heterogeneity may emerge in patients with the same residual coagulation factor activity, as well as different haemostatic and clinical outcomes during the same medication and dosage may occur (5-8). Therefore, there is a strong demand for an exploratory modality concerning the dynamics of global haemostasis, and the biological and clinical impact of therapy.

It is generally accepted that clotting factor assays do not always provide a reliable result of clinical efficacy of the treatment. These traditional coagulation tests are suitable for detecting and scoring congenital deficiencies of procoagulant factors. It is unlikely to account them for the total amount of thrombin potential and for the global pro- and anticoagulant promoters present in a whole blood sample. This is a more stringent reality in haemophilia with inhibitors. A reliable, simple and easily accessible, preferably bed-side test has been a long-awaited tool for monitoring the haemostatic performance of haemophilia therapies in life-threatening bleedings or for preventing such bleeds. In haemophilia with inhibitors and surgery it gains the significance of life-saving importance (7, 9-11).

\section{Objectives}

Our aims were:

-to perform a comparative analysis of the haemostatic impact of BPAs in severe haemophilia complicated by high titer inhibitors using three types of exploratory tests: traditional coagulation assays and novel exploratory methods like the TEG (Thromboelastogram) and the TGA (Thrombin Generation Assay) and - to correlate the biological results with clinical outcomes.

\section{Patients and methods}

\section{Subjects}

Seven persons with severe haemophilia A (SHA), complicated with high titer inhibitors $(>5 \mathrm{BU} /$ $\mathrm{ml}$ ), treated with recombinant activated Factor VII (rFVIIa) or activated prothrombin complex concentrate (APCC) in 12 situations (6 with rFVIIa, 5 with APCC and 1 with both BPAs), 5 of them with invasive/surgical intervention were explored (Table 1).

A comparative evaluation of the parameters under focus was also conducted in a control healthy volunteer group of 15 persons belonging to the same age group as in the haemophilia patients group. The study was approved by the institutional Ethics Committee and began after the informed consent of investigated persons was given.

\section{Blood sampling}

Whole blood was collected in sodium citrate collection tubes. For routine coagulation test and thrombin generation assay, samples were centrifuged twice at $2900 \mathrm{~g}$ for 10 minutes at room temperature in order to obtain platelet poor plasma (PPP). For TGA, PPP was frozen at $-70^{\circ} \mathrm{C}$ until the measurement was performed. For TEG evaluation 0,2 M Calcium chloride and whole blood mixed with kaolin was used.

All preanalytical and analytical procedures were performed alike for both groups: control group and haemophilia subjects. 
Table 1. SHA complicated with inhibitors patients included in the study

\begin{tabular}{|c|c|c|c|c|c|c|c|c|c|c|c|c|}
\hline \multirow{2}{*}{ そ̊ } & \multirow{2}{*}{\multicolumn{2}{|c|}{ 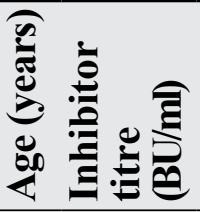 }} & \multirow{2}{*}{$\begin{array}{c}\text { Patholo- } \\
\text { gical state }\end{array}$} & \multirow{2}{*}{$\begin{array}{c}\text { Surgical } \\
\text { invasive } \\
\text { interven- } \\
\text { tions }\end{array}$} & \multirow[b]{2}{*}{ BPAs } & \multicolumn{2}{|c|}{ aPTT } & \multicolumn{2}{|c|}{ TEG } & \multicolumn{2}{|l|}{ TGA } & \multirow{2}{*}{$\begin{array}{r}\text { Clinical } \\
\text { - response } \\
\text { RSTRBE }\end{array}$} \\
\hline & & & & & & $\begin{array}{l}\text { Post } \\
\text { 1h }\end{array}$ & $\begin{array}{l}\text { Post } \\
4 h\end{array}$ & $\begin{array}{c}\text { Post } \\
\text { 1h }\end{array}$ & $\begin{array}{l}\text { Post } \\
4 \mathrm{~h}\end{array}$ & $\begin{array}{l}\text { Post } \\
1 \mathrm{~h}\end{array}$ & $\begin{array}{l}\text { Post } \\
4 \mathrm{~h} \\
\end{array}$ & \\
\hline \multirow[b]{2}{*}{ P1 } & \multirow[b]{2}{*}{7} & \multirow[b]{2}{*}{239} & \multirow{2}{*}{$\begin{array}{l}\text { Femur } \\
\text { fracture with } \\
\text { displacement } \\
\text { Subdural } \\
\text { haematoma }\end{array}$} & $\begin{array}{c}\text { CVC } \\
\text { insertion }\end{array}$ & rFVIIa; & $\mathrm{NCV}$ & $\mathrm{NCV}$ & $\mathrm{CV}$ & $\mathrm{CV}$ & $\mathrm{CV}$ & $\mathrm{CV}$ & none \\
\hline & & & & $\begin{array}{l}\text { Femural } \\
\text { osteo- } \\
\text { synthesis }\end{array}$ & $\begin{array}{l}\text { rFVIIa+ } \\
\text { APCC }\end{array}$ & $\mathrm{NCV}$ & $\mathrm{NCV}$ & $\mathrm{CV}$ & PCV & $\mathrm{CV}$ & $\mathrm{CV}$ & good \\
\hline \multirow[b]{2}{*}{ P2 } & \multirow[b]{2}{*}{22} & \multirow[b]{2}{*}{7.64} & $\begin{array}{l}\text { Psoas hae- } \\
\text { matoma }\end{array}$ & - & rFVIIa & $\mathrm{NCV}$ & $\mathrm{NCV}$ & $\mathrm{CV}$ & $\mathrm{CV}$ & $\mathrm{CV}$ & $\mathrm{CV}$ & good \\
\hline & & & $\begin{array}{l}\text { Recurrent } \\
\text { haemarthro- } \\
\text { sis (ankle, } \\
\text { elbow) }\end{array}$ & - & APCC & $\mathrm{NCV}$ & $\mathrm{NCV}$ & $\mathrm{CV}$ & PCV & $\mathrm{CV}$ & $\mathrm{CV}$ & good \\
\hline \multirow[b]{2}{*}{ P3 } & \multirow[b]{2}{*}{26} & \multirow[b]{2}{*}{74} & $\begin{array}{l}\text { Recurrent } \\
\text { shoulder hae- } \\
\text { marthrosis }\end{array}$ & & fFVIIa & $\mathrm{NCV}$ & $\mathrm{NCV}$ & $\mathrm{CV}$ & $\mathrm{CV}$ & $\mathrm{CV}$ & $\mathrm{CV}$ & excellent \\
\hline & & & $\begin{array}{l}\text { History } \\
\text { bilateral } \\
\text { thigh ampu- } \\
\text { tation }\end{array}$ & & APCC & $\mathrm{NCV}$ & $\mathrm{NCV}$ & $\mathrm{CV}$ & PCV & $\mathrm{CV}$ & $\mathrm{CV}$ & excellent \\
\hline \multirow[b]{2}{*}{ P4 } & \multirow[b]{2}{*}{25} & \multirow[b]{2}{*}{32.8} & Multiple & \multirow{2}{*}{$\begin{array}{c}\text { Knee syno- } \\
\text { vectomy }\end{array}$} & fFVIIa & $\mathrm{NCV}$ & $\mathrm{NCV}$ & $\mathrm{CV}$ & $\mathrm{CV}$ & $\mathrm{CV}$ & $\mathrm{CV}$ & excellent \\
\hline & & & $\begin{array}{l}\text { chronic } \\
\text { arthopathy }\end{array}$ & & APCC & $\mathrm{NCV}$ & $\mathrm{NCV}$ & $\mathrm{CV}$ & PCV & $\mathrm{CV}$ & $\mathrm{CV}$ & excellent \\
\hline P5 & 18 & 20 & $\begin{array}{l}\text { Chronic art- } \\
\text { ropathy, with } \\
\text { extension } \\
\text { contracture }\end{array}$ & $\begin{array}{c}\text { Achilles } \\
\text { tendon } \\
\text { lengthening }\end{array}$ & rFVIIa & $\mathrm{NCV}$ & $\mathrm{NCV}$ & $\mathrm{CV}$ & $\mathrm{CV}$ & $\mathrm{CV}$ & $\mathrm{CV}$ & good \\
\hline \multirow{2}{*}{ P6 } & \multirow{2}{*}{45} & \multirow{2}{*}{49.28} & $\begin{array}{l}\text { Infection of } \\
\text { knee pros- } \\
\text { thesis }\end{array}$ & \multirow{2}{*}{$\begin{array}{c}\text { Thigh } \\
\text { amputation }\end{array}$} & fFVIIa & $\mathrm{NCV}$ & $\mathrm{NCV}$ & $\mathrm{CV}$ & $\mathrm{CV}$ & $\mathrm{CV}$ & $\mathrm{CV}$ & none \\
\hline & & & $\begin{array}{l}\text { Chronic os- } \\
\text { teomyelitis } \\
\text { Sepsis }\end{array}$ & & $\begin{array}{l}\text { rFVIIa }+ \\
\text { APCC }\end{array}$ & $\mathrm{NCV}$ & $\mathrm{NCV}$ & $\mathrm{CV}$ & PCV & $\mathrm{CV}$ & $\mathrm{CV}$ & excellent \\
\hline P7 & 7 & 6 & $\begin{array}{l}\text { Recurrent } \\
\text { knee hae- } \\
\text { marthrosis }\end{array}$ & - & APCC & $\mathrm{NCV}$ & $\mathrm{NCV}$ & $\mathrm{CV}$ & PCV & $\mathrm{CV}$ & $\mathrm{CV}$ & good \\
\hline
\end{tabular}

(SHA - severe haemophilia A; P - patient; rFVIIa - recombinant activated factor VII; APCC - Activated Prothrombin Complex Concentrate; RSTRBE - Rating Scale for Treatment Response of Bleeding Episodes, CVcorrected value $(p<0.05)$; NCV-not corrected value ( $p>0.05)$; $P C V$ - partially corrected value $(p=0.05-0.1)$.) 
Table 2. Average and SD values for all tested parameters in healthy controls versus SHA patients with inhibitors

\begin{tabular}{lcccc}
\hline Test type & $\begin{array}{c}\text { Parame- } \\
\text { ters }\end{array}$ & Healthy controls & $\begin{array}{c}\text { P w H inhibitors } \\
\text { (basal values) }\end{array}$ & p value \\
\hline \multirow{2}{*}{$\begin{array}{l}\text { Coagulo- } \\
\text { metric tests }\end{array}$} & APTT & $27.26 \pm 3.08$ & $88.50 \pm 18.84$ & 0.001 \\
\cline { 2 - 5 } & PT & $11.28 \pm 0.95$ & $11.78 \pm 0.44$ & 0.14 \\
\hline \multirow{3}{*}{ TEG } & PI & $99.80 \pm 11.68$ & $95.08 \pm 3.69$ & 0.27 \\
\cline { 2 - 5 } & K & $4.91 \pm 1.31$ & $85.52 \pm 48.71$ & 0.01 \\
\hline \multirow{nyyyy}{*}{ TGA } & MAg time & $2.34 \pm 0.60$ & $30.32 \pm 15.46$ & 0.01 \\
\cline { 2 - 5 } & ETP & $58.37 \pm 4.13$ & $47.14 \pm 9.96$ & 0.03 \\
\cline { 2 - 5 } & PEAK & $2.87 \pm 0.51$ & $2.59 \pm 0.29$ & 0.07 \\
\cline { 2 - 5 } & ttpeak & $199.03 \pm 53.20$ & $758.32 \pm 132.01$ & 0.21 \\
\cline { 2 - 5 } & start tail & $20.49 \pm 2.97$ & $54.95 \pm 9.89$ & $<0.001$ \\
\cline { 2 - 5 } & velindex & $76.03 \pm 26.44$ & $10.35 \pm 3.13$ & 0.01 \\
\hline
\end{tabular}

(SHA - severe haemophilia A; PwH-patients with haemophilia; TEG -thrombelastography; TGA - thrombin generation assay; APTT - Activated Partial Thromboplastin Time (s), PT-Prothrombin Time (s), PI-Prothrombin Index $(\%), R$ - reaction time (s), K- kinetics(s),MA - maximum amplitude(mm), ETP-endogenous thrombin potential (nM*min), ttpeak - time to peak (s) and velindex - velocity index (nM/min).)

\section{Measurements}

Routine coagulation tests: Activated Partial Thromboplastin Time (APTT), Prothrombin Time PT) and Prothrombin Index (PI) were performed using ACL Elite Pro coagulation analyzer through nephelometry method. (12)

Viscoelastic properties (rate, strength, stability) were analyzed by a thrombelastograph System 5000 (Haemoscope Corporation). Several parameters were measured: reaction time (s) (R), kinetics (s) (K) and maximum amplitude (mm) (MA). $(5,13)$

Thrombin generation assay (TGA) was performed using the Fluoroskan-Stago analyzer. For the continuous measurement of the fluorescent signal given by clotting plasma along with fluorescent substrate as activator, $5 \mathrm{pM}$ tissue factor and $4 \mathrm{uM}$ phospholipid reagent were used. Thrombin calibrator (known thrombin concentration) was used for each sample in order to correct individual differences in color of plasma and inner effect. The following parameters were analyzed by means of a dedicated software: lag time (s), endogenous thrombin potential (nM*min) (ETP), peak height (nM), time to peak (s) (ttpeak), start tail (min), and velocity index (nM/min). $(2,4,14)$

Clinical evaluation of BPAs efficacy was performed by a 4-point scale (Rating Scale for 
Treatment Response of Bleeding Episodes), in dependence on the relief of pain and objective signs of bleeding in a given period of time, the results being expressed as follows: excellent, good, fair, and none, where "none" was defined as a treatment failure. (15)

\section{Statistical analysis}

Results were given as mean values \pm SD for continuous variables. Data were analyzed using unpaired $\mathrm{t}$ test with Microsoft Excel version 2007; $<<0.05$ was considered as cut-off level for significance.

\section{Results}

A comparative evaluation of the focused parameters in a control healthy group versus SHA patients with inhibitors (basal values) revealed significant differences, presented in Table 2. Most remarkable were: the significant prolongation of APTT in coagulogram, prolonged $\mathrm{R}$ and $\mathrm{K}$ and reduction of $\mathrm{MA}$ at TEG, decreased peak, and extension of ttpeak, start tail and shortening of velocity index at TGA.

BPAs after 1 hour and 4 hours postadministration induced heterogeneous changes of the focused parameters.

rFVIIa did not have significant impact on conventional coagulometry parameters; but we have to mention the shortened PT and increased PI after rFVIIa administration, acceptable as "danger signals" for thrombotic accidents. It improved $\mathrm{R}$ and $\mathrm{K}$, and normalized MA on TEG. Concerning TGA, with the exception of ETP, all the other markers were significantly improved, with normalization of ttpeak and start tail (Table 3).

Regarding the impact of APCC (dosage of $50 \mathrm{IU} / \mathrm{kg}$ ) on our haemostatic values, with the exception of ttpeak, all the other parameters of conventional coagulometry, TEG and TGA improved in a non-significant manner (Table 4).
However, we have to stress the impossibility of TGA measurements after $100 \mathrm{IU} / \mathrm{kg}$ APCC at one hour post-administration due to the too high thrombin generation, only lower dosages (50 IU/ $\mathrm{kg}$ ) giving measurable parameters.

Concerning the correlation between the biological and the clinical outcome, it was difficult to be estimated, because of the small number and heterogeneity of bleeding events of patients. It should be mentioned that in two patients, P1 and P6, despite improved TEG and relatively normalized TGA parameters, they continued to bleed, making the addition of a second alternative BPA mandatory.

\section{Discussion}

Monitoring haemostatic response of therapy in severe haemophilia, especially with high titer inhibitors can still be a challenging task with a high burden of uncertainties. The existing conventional laboratory assays quantify the amount of coagulation factor, which is very useful from a diagnostic point of view. However, they are limited in their ability to fully evaluate the clot forming capability of the patients. In particular, in patients with inhibitors, the prediction of the global haemostatic potential is difficult or even impossible to be assessed. Unfortunately, to date, no routine laboratory test has been found suitable to monitor efficacy and the safety profile of BPAs. Therefore, this field is hampered even now by the lack of an accessible laboratory test able to predict optimal medication, dosage, intervals of administration and monitoring of efficacy. $(1,5)$

Taking into consideration the life-threatening risks of bleeding events and the life- and limbsaving significance of a tailored haemostatic treatment, a proper, adequate haemostatic investigation, giving a reliable image of the global haemostatic process, remains of utmost importance. The unpredictable clinical response 
Table 3. Statistical evaluation of parameters PRE-, POST- 1 hour and -4 hours administration of rFVIIa

\begin{tabular}{|c|c|c|c|c|c|c|}
\hline \multirow{2}{*}{ Test type } & \multirow{2}{*}{$\begin{array}{c}\text { Parame- } \\
\text { ters }\end{array}$} & \multicolumn{3}{|c|}{ Average } & \multicolumn{2}{|c|}{ p value } \\
\hline & & PRE & POST $1 \mathrm{~h}$ & POST $4 \mathrm{~h}$ & pre- $1 \mathrm{~h}$ & pre-4h \\
\hline \multirow{3}{*}{$\begin{array}{l}\text { Coagulo- } \\
\text { metric tests }\end{array}$} & APTT & 89.20 & 74.98 & 82.78 & 0.19 & 0.57 \\
\hline & PT & 11.73 & 6.20 & 6.55 & $<0.001$ & 0.001 \\
\hline & PI & 95.48 & 250.00 & 242.50 & $<0.001$ & 0.001 \\
\hline \multirow{3}{*}{ TEG } & $\mathbf{R}$ & 81.08 & 16.18 & 22.75 & 0.01 & 0.01 \\
\hline & $\mathbf{K}$ & 27.95 & 5.43 & 8.73 & 0.009 & 0.01 \\
\hline & MA & 49.83 & 72.78 & 70.28 & 0.001 & 0.003 \\
\hline \multirow{6}{*}{ TGA } & lag time & 2.59 & 1.84 & 1.77 & 0.001 & 0.001 \\
\hline & ETP & 813.61 & 914.47 & 1061.83 & 0.39 & 0.20 \\
\hline & PEAK & 54.73 & 123.36 & 127.35 & 0.001 & 0.01 \\
\hline & ttpeak & 11.33 & 5.39 & 5.50 & 0.009 & 0.01 \\
\hline & start tail & 37.44 & 23.49 & 25.85 & 0.001 & 0.001 \\
\hline & velindex & 8.15 & 36.36 & 35.07 & 0.001 & 0.004 \\
\hline
\end{tabular}

(TEG -thrombelastography; TGA - thrombin generation assay; APTT - Activated Partial Thromboplastin Time (s), PT-Prothrombin Time (s), PI-Prothrombin Index (\%), $R$ - reaction time (s), $K$ - kinetics (s), $M A$ - maximum amplitude (mm), ETP - endogenous thrombin potential ( $\mathrm{nM}^{*}$ min), ttpeak - time to peak (s) and velindex - velocity index (nM/min).)

to BPA and the lack of laboratory tools are responsible for the fact that surgery in inhibitor patients is still a big challenge for the risk of both, bleeding accidents and thrombo-embolic complications. The tailoring of therapy and provision of a personalized treatment, avoiding too low or too high dosage of BPA, are mandatory for the safety of the patients and also for the proper economic consumption of a very expensive medication. (16)

In our experience, conventional coagulometry was not a reliable tool for assessing the efficacy of BPAs: despite lowering the APTT values, neither rFVIIa, nor APCC could bring statistically significant changes; PT and PI behaved like "danger signals", both reaching risky levels for a thrombotic event.

Regarding the changes of the viscoelastic properties of TEG under BPAs, all the parameters: $\mathrm{R}, \mathrm{K}$, and MA improved, but still not reaching normal values during 4 hours of observation in both rFVIIa and APCC therapy.

Within the frame of TGA investigation, we observed the prompt and lasting correction of time to peak and of peak, start tail and velocity index under BPAs. During the survey of the small number of patients treated with APCC we assessed the fact that the dimension of the 
Table 4. Statistical evaluation of parameters PRE-, POST- 1 hour and -4 hours administration of APCC

\begin{tabular}{lcccccc}
\hline \multirow{2}{*}{ Test type } & $\begin{array}{c}\text { Parame- } \\
\text { ters }\end{array}$ & PRE & POST 1 h & POST 4 h & pre- 1h & pre-4h \\
\cline { 2 - 7 } & APTT & 141.10 & 77.38 & 70.60 & 0.32 & 0.28 \\
\cline { 2 - 7 } $\begin{array}{l}\text { Coagulo- } \\
\text { metric tests }\end{array}$ & PT & 10.20 & 9.33 & 10.55 & 0.59 & 0.83 \\
\cline { 2 - 7 } & PI & 137.98 & 151.13 & 122.05 & 0.76 & 0.71 \\
\hline \multirow{3}{*}{ TEG } & $\mathbf{R}$ & 58.33 & 21.4 & 48.78 & 0.03 & 0.56 \\
\cline { 2 - 7 } & $\mathbf{K}$ & 20.38 & 6.85 & 15.68 & 0.04 & 0.11 \\
\hline \multirow{3}{*}{ TGA } & MA time & 2.76 & 2.33 & 2.84 & 0.19 & 0.76 \\
\cline { 2 - 7 } & ETP & 803.09 & 1347.87 & 1663.73 & 0.04 & 0.02 \\
\cline { 2 - 7 } & PEAK & 63.41 & 148.68 & 154.45 & 0.01 & 0.03 \\
\cline { 2 - 7 } & ttpeak & 8.5 & 7.11 & 7.62 & 0.04 & 0.04 \\
\cline { 2 - 7 } & start tail & 34.71 & 25.56 & 33.12 & 0.09 & 0.75 \\
\cline { 2 - 7 } & velindex & 11.51 & 31.25 & 33.62 & 0.21 & 0.18 \\
\hline
\end{tabular}

(TEG -thrombelastography; TGA - thrombin generation assay; APTT - Activated Partial Thromboplastin Time (s), PT-Prothrombin Time (s) , PI - Prothrombin Index (\%), $R$ - reaction time (s), K- kinetics (s), MA - maximum amplitude $(\mathrm{mm})$, ETP - endogenous thrombin potential ( $n M^{*}$ min), ttpeak - time to peak (s) and velindex - velocity index (nM/min).)

increase of the above mentioned parameters was too high after administration of $100 \mathrm{IU} / \mathrm{kg}$ in order to be registered by TGA, and only the later values at 4,8 or 12 hours could be measured; on the other hand, it should be mentioned that a dosage of only $50 \mathrm{IU} / \mathrm{kg}$ did not give highly significant improvements of TEG and TGA parameters. Regarding the behavior of TEG and TGA values post-rFVIIa, it is worthwhile to underline the persistent normalization of time to peak, of peak, start tails and velocity index even at 4 hours post administration. These findings could suggest that a dosage for APCC of 75 IU/ $\mathrm{kg}$ would be preferable $(50 \mathrm{IU} / \mathrm{kg}$ - too low and
$100 \mathrm{IU} / \mathrm{kg}$ - too high) and that a prolongation of the intervals between administrations of rFVIIa would be safe, hypothesis which should be proved further on a larger number of explorations. (17)

What concerns the correlation between haemostatic impact and clinical outcome it seems to be a reality in our small cohort of patients. Nevertheless, it is not to be overlooked that in two patients, despite the persistent good TGA values, they continued to bleed and the addition of the second BPA was mandatory, assuring the stop of the hemorrhage. That is understandable if we consider the multifactorial dependence of global hemostasis: beside thrombinogenesis, also 
other factors (platelets, endothelial determinants, fibrinolytic factors, a.s.o.) being simultaneously involved. $(5,18-20)$

\section{Concluding remarks}

The rather small number of investigated patients, the heterogeneity of BPAs and their dosage, the lack of a strong standardization of the techniques limit the objectivity and reliability of the interpretation of our data. Nonetheless, in the present exploratory clinical practice, the combined use of TEG and TGA may be considered as unique source for useful surrogate markers indispensable in the monitoring of patients with inhibitors, able to provide more informative and complementary data on the haemostatic effects of BPAs in correlation with the clinical outcomes. They can support a tailored, personalized, more effective and safe therapy and at the same time a more efficient attitude from the point of view of cost-effectivity.

\section{References}

1. Tripodi A. The Long-Awaited Whole-Blood Thrombin Generation Test. Clin Chem. 2012;58(8):1173-5. DOI: 10.1373/clinchem.2012.189266

2. Hemker HC, Giesen P, AlDieri R, Regnault V, de Smed E, Wagenvoord R, et al. The Calibrated Automated Thrombogram (CAT): a universal routine test for hyper- and hypocoagulability. Pathophysiol Haemost Thromb. 2002;32:249-53. DOI: 10.1159/000073575

3. Marcus D Lance. A general review of major global coagulation assays: thrombelastography, thrombin generation test and clot waveform analysis. Lance Thrombosis J. 2015;13:1. DOI: 10.1186/1477-9560$13-1$

4. Kern A, Varnai K, Vasarhelyi B. Thrombin generation assays and their clinical application. Orv Hetil. 2014; 155 (22):851-7. DOI: 10.1556/OH.2014.29899

5. Young G, Sorensen B, Dargaud Y, Negrier C, BrummelZiedins $\mathrm{K}$, Nigel S, et al. Thrombin generation and whole blood viscoelastic assays in the management of hemophilia: current state of art and future perspec- tives. Blood. 2013; 121 (11):1944-50. DOI: 10.1182/ blood-2012-08-378935

6. Mancuso ME, Fasulo MR. Thrombin Generation Assay as a Laboratory Monitoring Tool during Bypassing Therapy in Patients with Hemophilia and Inhibitors. Semin Thromb Haemost. 2016;42:30-5.

7. Mancuso ME, Chantaragkul V, Clerici M. Low thrombin generation during major orthopedic surgery fails to predict bleeding risk in inhibitor patients treated with bypassing agents. Haemophilia. 2016;22(4):292-30. DOI: $10.1111 /$ hae.12939

8. Turecek PL, Varadi K, Keil B, Negrier C, Berntorp E, Astermark J, et al. Factor VIII inhibitor-bypassing agents act by inducing thrombin generation and can be monitored by a thrombin generation assay. Pathophysiol Haemost Thromb. 2003;33 (1):16-22. DOI: $10.1159 / 000071637$

9. Dargaud Y, Lienhart A, Meunier S, Hequet O, Chavanne $\mathrm{H}$, Chamouard V, et al. Major surgery in a severe haemophilia A patient with high titre inhibitor: use of the thrombin generation test in the therapeutic decision. Haemophilia.2005;11(5):552-8. DOI: $10.1111 /$ j.13652516.2005.01141.x

10. 1Dargaud Y, Lienhart A, Negrier C. Prospective assessment of thrombin generation test for dose monitoring of bypassing therapy in hemophilia patients with inhibitors undergoing elective surgery. Blood. 2010; 116 (25):5734-7. DOI: 10.1182/blood-2010-06-291906

11. Mancuso ME, Chantarangkul V, Clerici M. Thrombin generation assay in hemophilic patients with or without inhibitors undergoing orthopedic surgery. Haemophilia. 2014; 20 (3):10.

12. Instrumentation laboratory ACL ELITE* / ELITE PRO System. Reagents, controls and calibrators package's inserts. PN 722277 Rev. BB (November 2010) Beckman Coulter, Inc.

13. Shima M, Matsumoto T, Ogiwara K New assays for monitoring haemophilia treatment. Haemophilia. 2008;3:83-92. DOI: 10.1111/j.1365-2516.2008.01737.x

14. Ninivaggi M, Apitz-Castro R, Dargaud Y, de Laat B, Coenraad Hemker H, Lindhout $\mathrm{T}$, et al. WholeBlood Thrombin Generation Monitored with a Calibrated Automated Thrombogram-Based Assay. Clin Chem. 2012; 58 (8):1252-9. DOI: 10.1373/ clinchem.2012.184077 
15. Mahlangu J, Kuliczkowski K, Karim FA, Stasyshyn O, Kosinova MV, Lepatan LM, et al. Efficacy and safety of rVIII-SingleChain: results of a phase $1 / 3$ multicenter clinical trial in severe hemophilia A. Blood. 2016; 128 (5): 630-637. DOI: 10.1182/blood-2016-01-687434

16. Sorensen B, Ingerslev J. Tailoring haemostatic treatment to patient requirements - an update on monitoring haemostatic response using thrombelastography. Haemophilia. 2005; 11 (1):1-6. DOI: 10.1111/j.13652516.2005.01156.x

17. Négrier C, Gomperts ED, Oldenburg J. The history of FEIBA: a lifetime of success in the treatment of haemophilia complicated by an inhibitor. Haemophilia. 2006;12:4-13. DOI: 10.1111/j.13652516.2006.01379.x

18. Dargaud Y, Prevost C, Lienhart A, Bordet JC, Negrier C. Evaluation of the overall haemostatic effect of recombinant factor VIIa by measuring thrombin generation and stability of fibrin clots. Haemophilia. 2011;17:957-61. DOI: 10.1111/j.1365-2516.2011.02526.x

19. Vila V, Aznar JA, Moret A, Marco A, Navarro S, Vila C, et al. Assessement of the thrombin generation assay in haemophilia: comparative study between fresh and frozen platelet-rich plasma. Haemophilia. 2013;19:31821. DOI: $10.1111 /$ hae. 12044

20. Perrin J, Depasse P, Lecompte T. Large external quality assessment survey on thrombin generation with CAT: further evidence for the usefulness of normalization with an external reference plasma. Thromb Res. 2016;135(1):125-130. 